\title{
Bases para el análisis económico de los Sistemas de compliance penal')
}

\section{Bases for the Economic Analysis of Criminal Compliance Systems}

\author{
Diego Hernán Goldman ${ }^{(*)}$ \\ Universidad de Palermo
}

\begin{abstract}
Resumen: Los programas de compliance y los sistemas de responsabilidad penal o administrativa de las personas jurídicas constituyen en la actualidad herramientas crecientemente adoptadas por las distintas legislaciones para intentar disminuir el costo social de la criminalidad económica. Sin embargo, la incorporación legislativa y la aplicación de estos instrumentos legales no siempre está acompañada de una adecuada ponderación respecto de sus efectos sobre el bienestar social, los niveles de actividad económica y el funcionamiento de los mercados de bienes y servicios. Ello puede conducir, eventualmente, a efectos indeseados como la ineficiencia del sistema penal, la disminución de la actividad económica o el surgimiento de obstáculos a la competencia. Teniendo en cuenta estas circunstancias, en el presente trabajo recurriremos a las herramientas que brinda el Análisis Económico del Derecho para analizar la lógica que inspira a estos institutos jurídicos y los incentivos que generan, con el propósito de delinear algunos parámetros que permitan a legisladores, funcionarios judiciales, asesores jurídicos y a los propios empresarios evaluar los distintos sistemas de compliance en términos de eficiencia económica, generación de riquezas y promoción de la competencia en los mercados.
\end{abstract}

Palabras clave: Compliance - Análisis Económico del Derecho Penal - Responsabilidad Penal de las Personas Jurídicas - Delitos Económicos.

Abstract: Compliance programs and systems of criminal or administrative liability are being increasingly adopted by different countries as measures meant to reduce the social cost of white collar criminality. However, the legal application of these measures does not always ponder correctly the impacts on common good, the levels of economic activity and the adequate functioning of markets of goods and services. Eventually, this situation can lead to undesired effects, such as the inefficiency of the criminal system, the reduction of economic activity or the arising of obstacles to competition. By taking these circumstances into account, in this paper we will utilize the Economic Analysis of Law to analyze the logic that inspires these legal institutes and the incentives they generate. Our objective is to delineate some parameters that allow legislators, judges, legal advisors and businessmen to evaluate different compliance systems in terms of economic efficiency, generation of wealth and the promotion of competition in markets.

Keywords: Compliance - Economic Analysis of Criminal Law - Criminal Liability of Corporations - White Collar Crimes.

\footnotetext{
(*) Nota del editor: el artículo fue recibido el 10 de noviembre y aprobada su publicación el 20 de noviembre de 2018.

${ }^{* *}$ Abogado por la Universidad de Buenos Aires. Magíster en Economía y Ciencias Políticas por la ESEADE. Docente de posgrado de la Universidad de Palermo. Director General de Asuntos Jurídicos del Ministerio de Seguridad de la República Argentina. Correo electrónico: goldman.diego@gmail.com.
} 


\section{Introducción}

De institución básicamente exótica del Derecho Corporativo anglosajón, los programas de compliance se han transformado en muy pocos años en el fetiche del Derecho Penal Económico hispanoparlante. Cada día se escribe más, se discute más y, fundamentalmente, se legisla más sobre ellos. Pero, ¿en qué consisten estos programas que las empresas crecientemente adoptan -o se ven inducidas a adoptar- para prevenir, investigar y eventualmente sancionar las conductas ilícitas cometidas en su seno? ¿Cuál es la lógica económica que inspira la creciente gravitación de estos sistemas de autorregulación corporativa en detrimento de las tradicionales herramientas utilizadas por el Derecho Penal para disuadir la denominada "criminalidad empresaria"? ¿Pueden estos nuevos instrumentos, si no son implementados de modo adecuado, convertirse en un obstáculo a la competencia en ciertos mercados e, incluso, a la actividad económica en su conjunto?

Sin perjuicio que, a lo largo de este trabajo, intentaré sentar algunos puntos de partida para dar respuestas a estos interrogantes (atinar a darles solución definitiva es faena que excede con mucho mi propósito y posibilidades en esta ocasión), puedo aventurar una hipótesis en relación a las causas de este estado de situación. Desde esta óptica, la aparición de los programas de compliance y las normas sobre responsabilidad "penal" de las personas jurídicas ${ }^{(1)}$ a las que están unidos de forma prácticamente indisoluble, son consecuencia de un proceso de expansión del Derecho Penal que lleva décadas y que ha puesto en tela de juicio muchas de las categorías tradicionales del Derecho Penal Liberal. Así, la privatización de las funciones de prevención, investigación y sanción de determinadas conductas ilícitas, implícita en la instrumentación de los programas de compliance, aparece como respuesta frente a la impotencia de un Derecho Penal que carece de herramientas materiales y conceptuales para dar solución a la innumerable cantidad de problemáticas sociales, económicas y medioambientales en las que ha sido llamado a intervenir en los últimos años.

Dentro de esta lógica, un sistema en el que las propias empresas se hacen cargo de implementar los mecanismos tendientes a disuadir la actividad ilícita de sus directivos y dependientes, y en el que el Estado se reserva la potestad de intervenir para sancionar la insuficiencia o ineficacia de esos instrumentos -desligado ya, en la práctica, de la atadura consistente en la necesidad de tener que probar la existencia de una acción típica atribuible a título de dolo o culpa-, aparece como la forma menos onerosa de intentar satisfacer las demandas sociales en pos de respuestas a cuestiones tan disímiles como la corrupción administrativa, el lavado de dinero o los daños al medioambiente o a la salud de los consumidores.

Corresponde, sin embargo, dejar planteada aquí una advertencia: que la delegación en las propias empresas de las funciones de prevenir e investigar ciertos hechos ilícitos ocurridos en su seno-instándolas para ello a adoptar programas de compliance- constituya para el Estado la forma menos costosa de dar una respuesta a casos particularmente difíciles de investigar y sancionar, no significa necesariamente que sea la opción económicamente más eficiente para la sociedad en su conjunto. Podrían existir casos en los que, en efecto, el costo social neto de disuadir determinados hechos resultara superior a través de la implementación de los programas de compliance que recurriendo a las herramientas tradicionales que ofrece el Derecho Penal Liberal y que no incluyen la posibilidad de sancionar a las personas jurídicas. Un ejemplo de este supuesto podría ser el de los delitos cometidos por directivos de pequeñas empresas familiares, a las que instrumentar un sistema de compliance realmente eficaz puede resultarles prácticamente prohibitivo en función de su costo, a la vez que se trata de hechos relativamente fáciles de probar y sancionar mediante los mecanismos procesales y las categorías dogmáticas penales clásicas.

Inclusive, desde cierta perspectiva, como la sostenida por Rojas, podría resultar aún más eficiente que el Estado se desentienda de cualquier pretensión de reprimir e intentar disuadir determinadas conductas -ya sea por sí mismo o delegando esa función en las empresas- dejando que sean los propios particulares afectados quienes se encarguen de ello con sus propios recursos (Rojas 2000, 170). Yo mismo he defendido esta postura, al menos para determinados supuestos, concluyendo que una progresiva privatización de la acción penal tendría "(...) la virtud de permitir una asignación más eficiente de recursos en la sociedad (...)" (Goldman 2017, 58).

(1) Adelanto desde ya mi postura contraria a reconocer a las personas jurídicas como sujeto de las normas penales. En mi opinión, tal insistencia no tiene otra justificación que el aprovechamiento del contenido simbólico de las sanciones penales, que no podría ser alcanzado admitiendo la verdadera naturaleza administrativa de este tipo de sanciones. Por su parte, los intentos por construir conceptos de acción, dolo y culpa aplicables a las personas jurídicas que permitan superar las limitaciones propias de las categorías penales reflejadas en la máxima societas delinquere non potest, no sólo han resultado infructuosos, sino que además resultan amenazadores de los principios garantistas del Derecho Penal Liberal. En la legislación comparada existen diversos ejemplos en los que la responsabilidad de las personas jurídicas se circunscribe, a mi entender adecuadamente, al ámbito del Derecho Administrativo, tales como el Decreto Legislativo 231 del 8 de junio de 2001 en Italia, o la Ley 30424 en el Perú. 
Por otra parte, tampoco debemos perder de vista que, más allá de la eficiencia o ineficiencia en cada caso de los sistemas de compliance penal como medio de prevención de distintos delitos usualmente vinculados a la actividad empresarial, el modo en que el Derecho Penal reacciona frente a esas conductas ilícitas derrama sus efectos sobre otros aspectos de la vida social. De este modo, las opciones de política criminal en materia de delitos económicos pueden afectar, como ya se mencionó, aspectos tales como la competencia en los mercados o las posibilidades de acceso a los mismos para determinados tipos de empresas, los precios de ciertos bienes o servicios, e incluso el nivel general de actividad económica.

Como punto de partida para la reflexión sobre las cuestiones hasta aquí planteadas, el Análisis Económico del Derecho puede resultar una herramienta sumamente útil, que nos dará una perspectiva distinta a la que usualmente guía la indagación jurídica en nuestro medio, obligándonos a posar la mirada no ya sobre la justicia o injusticia de las categorías conceptuales e instituciones con las que abordamos los problemas vinculados a la criminalidad económica, sino sobre los incentivos y efectos concretos que éstas generan.

Ello así, entiendo conveniente, antes de proseguir con los demás tópicos propuestos, dedicar algunos párrafos a resumir brevemente en qué consiste y como funciona a grandes rasgos el Análisis Económico del Derecho Penal.

\section{Nociones básicas de Análisis Económico del Derecho Penal}

El Análisis Económico del Derecho no es otra cosa que la aplicación de las herramientas analíticas de la Economía -en particular, de la microeconomía- al estudio de las instituciones jurídicas. Ello implica partir de la base de que los individuos actúan racionalmente en pos de la maximización de sus beneficios particulares ${ }^{(2)}$, y que las normas jurídicas pueden influir sobre esas conductas, ya sea imponiendo mayores costos para quienes realicen actos socialmente indeseables, como incentivos para el caso contrario.

Por otra parte, el Análisis Económico pone de manifiesto que las normas e instituciones jurídicas llevan implícitos ciertos costos (por ejemplo, aquellos vinculados al sostenimiento del sistema judicial establecido para asegurar su vigencia) y tienen efectos sobre la generación y distribución de riqueza en la sociedad (por ejemplo, leyes mercantiles que favorezcan a los deudores por sobre los acreedores, pueden determinar una disminución del crédito y, por ende, de la inversión productiva).

Llevado al ámbito del Derecho Penal, el Análisis Económico impone dejar de lado las explicaciones antropológicas, sociológicas o psiquiátricas de los fenómenos delictivos para partir de una base mucho más sencilla, pero quizás de mayor potencial explicativo: que los delincuentes son personas racionales como el que más, y no actúan sino tratando de maximizar sus beneficios individuales. Ello no significa negar, desde luego, que puedan existir razones sociológicas o psicológicas que lleven a los individuos a incurrir en conductas consideradas delictivas, sino afirmar que el sistema penal puede estructurarse y resultar socialmente eficiente prescindiendo de indagar sobre tales motivaciones. Va de suyo que, en el ámbito de los ilícitos vinculados a la actividad empresarial, la hipótesis del delincuente maximizador parece aún más atractiva en sus aristas explicativas y prescriptivas, en la medida en que resulta claro que la actividad corporativa está orientada por el propósito de incrementar las ganancias de la empresa, y responde de modo más directo a los incentivos establecidos por el sistema jurídico.

Partiendo de esta hipótesis del delincuente como maximizador racional, el Análisis Económico del Derecho Penal deriva una serie de axiomas que, al decir de Gary Becker, buscan dar respuesta a interrogantes tales como cuántos recursos debería la sociedad emplear en reforzar el cumplimiento de sus leyes mediante la amenaza de la pena, qué tipos de ofensas deberían ser permitidas, o cuántos delincuentes deberían quedar impunes para maximizar el beneficio social total (Becker 1968, 170). El propósito del enfoque económico, en definitiva, es delinear un sistema penal "eficiente" que minimice el costo social del delito, persiguiendo sólo aquellas conductas que causan daños mayores al costo de su prevención, y graduando las penas de modo tal de alcanzar el máximo grado de disuasión al menor costo posible.

El punto de partida sobre el que reposa el Análisis Económico del Derecho Penal es, como ya lo esbozamos en los párrafos precedentes, la hipótesis de que los delincuentes actúan racionalmente en base a incentivos y con la expectativa de maximizar su beneficio personal: un individuo llevará a cabo un acto

(2) Cabe aclarar aquí que la maximización del beneficio individual que postula el AED no refiere necesariamente a la maximización de los ingresos monetarios del individuo, sino a la consecución de los fines con más alta ponderación en su escala de valores subjetiva, cualesquiera que sean. Así, existen individuos más interesados en incrementar su prestigio, realizar sus valores religiosos o simplemente agradar al prójimo, que en obtener beneficios mensurables en dinero. Todos ellos actuarán racionalmente, en un sentido económico, en la medida en que sus acciones resulten a priori consistentes con el propósito de alcanzar esos fines. 
ilícito en la medida en que estime que sus beneficios potenciales resultarán superiores a los costos esperados, de lo contrario se abstendrá de actuar. Siguiendo este razonamiento, podríamos pronosticar que un potencial ladrón sólo intentará un robo si el valor de los bienes con los que espera alzarse resulta para él superior al valor que asigna al tiempo que podría pasar en prisión en caso de ser descubierto por las autoridades y condenado o, para ser más exactos, al valor actual que otorga a ese tiempo al multiplicarlo por la probabilidad que, estima, tiene de ser juzgado y condenado. De lo contario, esto es, si el beneficio esperado del delito resulta inferior a su costo estimado(3), el sujeto optará por dedicar su tiempo a otro tipo de actividad.

Como derivación de este axioma fundamental del delincuente como maximizador racional, el Análisis Económico del Derecho Penal postula que es posible disuadir la comisión de delitos elevando su costo esperado a través de la manipulación de sus componentes: la probabilidad y la magnitud de la sanción. En este sentido, Becker afirma que, de mantenerse constantes las demás variables, un incremento en la probabilidad de que el delincuente sea condenado, o un incremento en la magnitud del potencial castigo, conducirá, en mayor o menor medida, a la reducción del número de individuos dispuestos a cometer delitos (Becker 1968, 176).

En paralelo al estudio de los incentivos que tienen los individuos para cometer o no delitos, el Análisis Económico del Derecho Penal postula que es también necesario ponderar el costo social del delito, consistente en el daño que éste causa a las víctimas y al resto de la sociedad, y el costo de la disuasión, dado por los gastos necesarios para poner en funcionamiento el aparato policial, judicial y penitenciario destinado a detectar, juzgar y sancionar esos ilícitos.

Desde el punto de vista de la cuantificación del costo social del delito, es relativamente sencillo identificar aquellos daños irrogados directamente a la víctima: destrucción de sus bienes, privación de su libertad, lesiones corporales, etcétera. Algo más complicado resulta, por el contrario, determinar cuál es el daño que un delito ocasiona a aquellos individuos que no son ni la propia víctima ni sus allegados directos, excluyendo el caso, por supuesto, de aquellos delitos que afectan bienes jurídicos estatales o públicos, como el daño sobre inmuebles del Estado o la contaminación del medioambiente, en los cuales no existen mayores obstáculos para establecer el tipo de costo que el ilícito impone a una pluralidad determinada o indeterminada de individuos. En líneas generales, cabe sostener que el principal daño que el delito irroga a quienes no son sus víctimas directas, está dado por el sentimiento de temor a ser víctima de hechos similares, que constituye un costo social o daño público de suficiente entidad como para justificar la intervención estatal tendiente a su evitación. Como señala Nozick, "(...) hay un interés público y legítimo en eliminar estos actos de traspaso de límites, especialmente porque su comisión hace que todos tengan miedo de que les ocurra a ellos" (Nozick 1988, 74).

Por el lado de los costos de disuasión, existen diferentes erogaciones susceptibles de ser mensuradas monetariamente, tales como los gastos que insumen los sistemas policiales, judiciales y penitenciarios: edificios, sueldos, insumos de oficina, vehículos, infraestructura informática, etcétera. Estos costos, además, tienden a incrementarse proporcionalmente a medida que se busca aumentar el costo potencial del delito para los hipotéticos delincuentes, ya sea a través de la mejora en la probabilidad de condena, como en la intensificación de su severidad: para aumentar la probabilidad de atrapar a quienes han cometido delitos será necesario destinar fondos a aumentar la cantidad de policías en las calles, invertir en tecnología forense, capacitación del personal, etc.; a la vez que mantener a los condenados en las cárceles por un mayor lapso de tiempo incrementará los gastos de alojamiento y seguridad respectivos.

Como corolario de lo expuesto, podemos decir que, en términos económicos, el Derecho Penal será eficiente en la medida en que los costos de disuasión del delito tiendan a igualarse con su costo social. Ello en la medida en que, si los recursos invertidos en disuasión estuvieran por debajo del punto de igualación con el costo social del delito, todavía podría obtenerse un beneficio social marginal gastando sumas adicionales de dinero para incrementar el nivel de disuasión. Por el contrario, por encima de ese hipotético "punto de equilibrio", el costo de la disuasión "excedente" resultaría superior al beneficio social marginal de la reducción del delito obtenida, por lo que resultaría socialmente beneficioso permitir que se cometa un número mayor de delitos (Cooter y Ulen 1998, 564).

Aplicando estas ideas que acabo de explicar en forma muy rudimentaria, podemos entender la lógica económica que trasunta

(3) Damos por sentado que el principal componente de este costo estimado está dado por el valor de la pena esperada, es decir el monto de la pena prevista por la legislación para ese tipo de delitos, multiplicado por la probabilidad de que sea efectivamente aplicada. Sin embargo, existen otros costos que deberían ser incluidos en ese cálculo, siendo el más notorio de ellos el costo de oportunidad dado por el beneficio potencial de las actividades alternativas -lícitas o ilícitas- en que pudo emplearse el tiempo dedicado a cometer el delito, pero también costos psicológicos (por ejemplo, el posible sentimiento de culpa o remordimiento por haber realizado un acto moralmente reprochable) o sociales (por ejemplo, el eventual repudio de familiares y allegados respecto del hecho cometido), entre otros. 
la inclusión de las personas jurídicas como sujeto pasivo de sanciones penales y la consecuente irrupción de la institución del compliance.

Así, el problema principal que ofrece la criminalidad vinculada a la actividad empresarial, particularmente cuando se produce en el seno de grandes corporaciones transnacionales con actividades altamente diversificadas y esquemas societarios y organigramas de gran complejidad, es el alto costo de disuasión. La dificultad que este tipo de estructuras organizacionales impone para deslindar las responsabilidades individuales de sus directivos o dependientes, implica que en ocasiones resulte sumamente costoso para el aparato de justicia estatal poder aplicar sanciones efectivas dentro de un esquema de Derecho Penal tradicional, en el cual es necesario probar la existencia de una acción u omisión típica, antijurídica y culpable atribuible a un autor determinado, toda vez que ello acarrea una gran inversión de tiempo y recursos en investigación forense.

Como consecuencia de los altos costos implicados en la investigación y sanción de este tipo de ilícitos, la probabilidad de castigo y, por ende, el costo para el potencial delincuente tienden a ser bajos, generando incentivos para la actividad empresarial ilícita. A ello se suma que el tipo de hechos a los que nos referimos (evasión tributaria, corrupción administrativa, daños al medio ambiente, etcétera) suelen ser actividades con un beneficio potencial muy alto y que, a la vez, generan un costo social significativo(4).

Frente a este panorama desalentador (altos beneficios potenciales de la actividad ilícita, alto costo social del delito, altos costos de disuasión, bajo costo esperado para el potencial delincuente) el Derecho Penal Liberal asentado sobre la idea de la responsabilidad individual aparece como una herramienta bastante ineficaz para promover una asignación de recursos eficiente que maximice la riqueza social. Es aquí, precisamente, donde otras ramas del Derecho pueden concurrir en ayuda del Derecho Penal. En este sentido, la posibilidad de asignar a las propias personas jurídicas responsabilidad por los delitos cometidos por sus directivos o dependientes en su nombre o representación -responsabilidad que, insisto, por su naturaleza debería ser ubicada dentro del ámbito del Derecho Administrativo sancionador- aparece como un modo de incrementar el costo esperado de esos actos ilícitos, al mejorar la probabilidad de que sean efectivamente sancionados y al disminuir los costos del procedimiento para las autoridades. Por su parte, la adopción de programas de compliance por las propias empresas, ya sea por imposición del marco normativo vigente, o como medio voluntario para reducir hipotéticas pérdidas por multas u otro tipo de sanciones, ayuda también a la disminución de los costos de disuasión, en la medida que implican la internalización por parte de la persona jurídica de las erogaciones vinculadas a investigación del delito. Más adelante desgranaremos estas cuestiones con algo más de profundidad.

Finalmente, no quiero cerrar este apartado sin señalar que, así como el análisis económico nos otorga un sólido marco para explicar y justificar por qué en algunos casos resulta socialmente eficiente establecer esquemas de responsabilidad penal o administrativa de las personas jurídicas, también nos lleva a concluir que, en otros supuestos, mantener un estricto sistema de responsabilidad penal individual o, incluso, desincriminar ciertas conductas hoy tipificadas como delito, pueden resultar mejores opciones a la hora de minimizar el costo social del delito. En tal sentido, cabe advertir sobre cierta tendencia a aplicar teorías y herramientas jurídicas en forma indiscriminada, sin prestar atención a las particularidades de cada situación concreta y a las consecuencias prácticas que pueden acarrear. Un ejemplo claro puede ser el de delitos cometidos en nombre de pequeñas o medianas empresas familiares, que suelen protagonizar el grueso de los casos que llegan a los tribunales, donde el daño social causado por las conductas que se les atribuye es relativamente poco significativo y la identificación de los responsables de la toma de decisiones no ofrece mayores dificultades probatorias, por lo que mantener un esquema penal clásico de responsabilidad individual puede ser la opción económicamente más eficiente. En estos casos además debe evaluarse el hecho de que cargarles a las empresas el costo de implementar un programa de compliance podría, eventualmente, llevarlas a abandonar determinadas actividades productivas lícitas, lo que causaría un menoscabo en la generación de riqueza en la sociedad superior al valor del daño que se procura evitar.

Lamentablemente, las leyes, Ia jurisprudencia e incluso la doctrina, quizás partiendo de ciertos prejuicios bastante asentados en contra de la actividad empresarial, no siempre efectúan estas distinciones y aplican una única solución a situaciones evidentemente distintas. Cabe insistir, al respecto, que el análisis económico constituye

(4) El costo social en este tipo de delitos está compuesto casi exclusivamente por el daño directo a bienes colectivos tales como el patrimonio público o el medioambiente. Paradójicamente, y a excepción de los casos de daños por productos o desastres ambientales que pueden afectar la salud de un gran número de personas, el miedo a sufrir el delito como componente del costo social es prácticamente nulo: nadie teme ser víctima de grandes defraudadores o evasores de impuestos. 
una herramienta valiosa no sólo para tratar de orientar la política criminal hacia la adopción de procesos y sanciones óptimas, sino también para analizar cuándo el Derecho Penal puede resultar incluso una herramienta socialmente ineficiente.

\section{Concepto y contenido de los programas de compliance}

Con carácter previo a continuar con el análisis, me parece conveniente hacer aquí un breve paréntesis para definir con mayor precisión a qué nos referimos cuando hablamos de programas compliance y cuál ha de ser su contenido mínimo.

Al respecto, se ha apuntado que "(...) en el terreno jurídicopenal, la expresión compliance se emplea para designar única y exclusivamente la obligación de las personas jurídicas de establecer mecanismos internos que prevengan que determinadas personas físicas que ocupan puestos de relevancia dentro de ellas cometan un delito en beneficio de la empresa" (Arocena 2017, 129). A esta definición, parece útil agregar otros elementos característicos del objeto de los programas de compliance que son, además del propósito de disuadir conductas ilícitas, al que coadyuvan, la previsión de mecanismos para su detección, identificación de sus responsables y sanción tanto interna (a través de medidas de carácter disciplinario) como externa (mediante su comunicación oportuna a las autoridades pertinentes).

En el Derecho comparado podemos encontrar distintas definiciones legales de lo que se entiende por programa de compliance. En Argentina, el artículo 22 de la Ley 27.401 los caracteriza como "el conjunto de acciones, mecanismos y procedimientos internos de promoción de la integridad, supervisión y control, orientados a prevenir, detectar y corregir irregularidades y actos ilícitos"; mientras que el apartado 2 del artículo 31 bis del Código Penal español se refiere a ellos como los "modelos de organización y gestión que incluyen las medidas de vigilancia y control idóneas para prevenir delitos (...) o para reducir de forma significativa el riesgo de su comisión". De modo similar, en Chile, el artículo 3 de la Ley 20.393 se refiere a los programas de compliance haciendo alusión a "modelos de organización, administración y supervisión para prevenir delitos", y en Perú el inciso 13 del artículo 5 del Reglamento de la Ley 30.424 define a los "modelos de prevención" como el "sistema ordenado de normas, mecanismos y procedimientos de prevención, vigilancia y control, implementados voluntariamente por la persona jurídica, destinados a mitigar razonablemente los riesgos de comisión de delitos y a promover la integridad y transparencia en la gestión de las personas jurídicas".

En definitiva, cuando nos referimos a un programa de compliance, no estamos haciendo sino alusión al conjunto de medidas que una persona jurídica u organización deliberadamente adopta para disuadir, detectar y sancionar la comisión de actos ilícitos relacionados con su actividad y que puedan redundar en su provecho o beneficio, cometidos por sus miembros, directivos o dependientes.
Es importante resaltar que, además de contribuir a la prevención de la delincuencia corporativa, los programas de compliance deben constituir, cuando se encuentran adecuadamente diseñados y son eficaces, una salvaguarda que atenúe o elimine la responsabilidad de la persona jurídica por los delitos cometidos por los individuos que lograron saltear los mecanismos de control interno. El delito, en estos casos, debería ser considerado como un acto que no pudo evitarse ni aún mediante un comportamiento preventivo diligente, por lo que no debería generar la atribución de responsabilidad a la empresa, al faltar el presupuesto del déficit de organización (Montiel 2017, 33). De lo contrario, es decir, si la ley obliga a las empresas a establecer programas de cumplimiento, pero no los considera una eximente de responsabilidad si el delito igualmente se consuma, podría darse incluso la paradoja de que la responsabilidad de las personas jurídicas, en lugar de contribuir a disminuir las tasas de criminalidad económica, las termine alimentando al convertirse en un incentivo para la adopción de programas de prevención deliberadamente ineficaces. Como señala Posner:

"Otra crítica contra la responsabilidad penal corporativa consiste en que podría aumentar efectivamente la cantidad de delitos corporativos. Si los esfuerzos corporativos por impedir la comisión de delitos por los empleados corporativos aumentan simultáneamente la probabilidad de que se descubran los delitos, y de que se persigan luego, la corporación podría optar por reducir sus esfuerzos preventivos" (Posner 2007, 673-674).

Por lo general, atendiendo a estas ideas, las distintas legislaciones que prevén la responsabilidad penal o administrativa de las personas jurídicas contemplan precisamente que la adopción de un programa de compliance eficaz tenga un efecto eximente o cuanto menos atenuante respecto de las sanciones que pueden caberle al ente ideal. Un buen ejemplo en este sentido es la legislación peruana, que en el artículo 17.1 de la Ley 30.424 establece la exención de responsabilidad para la persona jurídica "si adopta e implementa en su organización, con anterioridad a la comisión del delito, un modelo de prevención adecuado a su naturaleza, riesgos, necesidades y características". Con algunos matices, 
podemos encontrar soluciones análogas en la legislación argentina (artículo 9 de la Ley 27.401) o española (artículo 31 bis, inciso 2, del Código Penal).

Está claro que, para tener este efecto eximente sobre la responsabilidad de la persona jurídica, el programa de cumplimiento normativo debe haber sido diagramado en función de las características y riesgos particulares de la organización que lo implementa, condiciones que no cumplen los programas genéricos que no pasan de ser meros instrumentos de mejora de la imagen corporativa (Palma Herrera 2017, 52). Entonces, ¿a qué pautas debería ajustarse, y qué elementos debería contener, un programa de compliance para ser considerado una herramienta adecuada de prevención del delito y, por ende, determinar la eliminación o atenuación de la responsabilidad de la persona jurídica por los ilícitos cometidos por sus directivos y dependientes?

Si bien cada legislación nacional en particular establece los distintos requisitos que debe cumplimentar un programa de compliance para resultar idóneo en orden a la atenuación o eliminación de la responsabilidad de la persona jurídica -que a su vez pueden tener carácter más o menos taxativo según el casopodemos identificar sin embargo ciertos elementos comunes a todas las legislaciones, y que en líneas generales constituyen el contenido mínimo que es dable exigir a estos sistemas de prevención interna.

Así, en primer lugar, el programa de compliance debe estar estructurado a partir de la identificación de un mapa de riesgos propio de la empresa, que determine qué tipos de delitos deben ser prevenidos en función de su actividad, modalidades de trabajo, características de su personal, vínculos comerciales, condiciones financieras, etc. (Palma Herrera 2017, 52).

Una vez identificados los riesgos potenciales, es decir las conductas delictivas que hipotéticamente podrían vincularse a la actividad de la empresa, será menester establecer los mecanismos de control adecuados para su prevención y detección. Estos podrán incluir aspectos tales como la adopción de un código de ética para la dirección y el personal del ente; el establecimiento de protocolos para la toma de decisiones relevantes; la creación de canales de denuncias que protejan la identidad del denunciante, tanto interno como externo, y los protejan contra eventuales represalias; procedimientos para comprobar la integridad de proveedores, clientes y demás socios de negocios; la designación de un responsable interno encargado del desarrollo, supervisión y coordinación del programa (compliance officer); un sistema de investigación interna apropiado, etcétera.

Finalmente, el programa de compliance debería contemplar un régimen disciplinario que permita sancionar rápida y eficazmente a los individuos que hubieran incurrido en actos ilícitos, así como mecanismos para informar esos hechos a las autoridades públicas en tiempo oportuno. Recordemos, en relación a este último aspecto, que uno de los propósitos que inspira la promoción del compliance es, precisamente, reducir los costos de investigación del sistema de justicia estatal, nutriéndolo de información relevante producida por las propias empresas, que facilite la identificación y sanción de los autores de delitos económicos.

Cumplidas estas pautas que demuestran la existencia de un compromiso real y tangible de la dirección de la persona jurídica con el apego a la normativa vigente y la disuasión de conductas ilícitas en su seno, el programa de compliance debería tener por efecto disminuir o eliminar la responsabilidad del ente ideal por los delitos cometidos en su nombre o beneficio dado que, de lo contrario, no existirían incentivos verdaderos para su adopción, aun cuando ésta sea impuesta obligatoriamente por la ley. En esta inteligencia, no puedo más que coincidir en que "(...) no basta con que la regulación legal recomiende, estimule e incluso disponga la conformación de un criminal compliance en la empresa, sino que deben darse, además, las condiciones para que tal conformación resulte económicamente atractiva para las empresas" (Arocena 2017, 136). Lamentablemente, hasta el momento la consideración judicial de los programas de compliance como elemento eximente o morigerador de la responsabilidad de las personas jurídicas parece ser bastante escasa, habiéndose señalado, por ejemplo, que en los Estados Unidos apenas fueron tenidos en cuenta para la graduación de la pena en tres casos en un lapso de diez años (Arocena 2017, 142), lo que revela una notoria incongruencia con el propósito legal de promover la adopción de estos sistemas de control interno.

\section{Función económica del compliance}

Vimos ya que, desde una perspectiva económica, el objetivo del sistema penal debería consistir en minimizar el costo social del delito, lo cual acontece por hipótesis cuando los costos de disuasión y el daño total causado por los delitos no disuadidos tienden a igualarse.

Dentro de esta óptica, pareciera ser que la idea de trasladar a los propios entes ideales las funciones de prevención, investigación y sanción de los delitos que actúan en el ámbito de estructuras societarias complejas, redundaría en una disminución de los costos asociados a la disuasión de esas conductas 
$y$, por ende, en una mayor eficiencia del sistema penal, en la medida en que podría evitarse una mayor cantidad de actos ilícitos a un costo menor.

Recordemos además que, por lo general, se trabaja sobre el supuesto de grandes corporaciones en las que, en virtud de la complejidad de sus estructuras, la dispersión y estratificación de la toma de decisiones, la transnacionalidad de sus operaciones y flujos financieros, etc., resulta altamente costoso para el sistema de justicia penal estatal, cuando no imposible, determinar la identidad de los autores y partícipes individuales de los delitos cometidos en su seno y reunir las pruebas para su enjuiciamiento y condena. En línea con este razonamiento, se ha señalado por ejemplo que los requisitos legales para la aplicación de penas a los individuos se "(...) topan con obstáculos probatorios de primer orden. Es complicado, en este sentido, marcar las relaciones de jerarquía o dependencia respecto de acciones concretas; es dificultoso señalar la información conocida por el subordinado o por el encargado; o es casi imposible encajar los escenarios de improvisación empresariales en el reparto funcional interno de las sociedades" (Pérez González 2015, 135).

Este cuadro de situación justificaría que se delegue en las propias personas jurídicas el diseño y gestión del sistema de prevención de ilícitos, habida cuenta de que, en virtud de su mayor cercanía a los hechos y su conocimiento respecto de los organigramas, circuitos de toma de decisiones, procesos financieros y contables -de los cuales la autoridad estatal, a priori, carece- se encontrarían no sólo en mejor posición para llevar a cabo dicha tarea, sino que además podrían realizarla a un costo menor. En este sentido, se ha señalado que esta "privatización" de ciertas funciones de prevención, investigación y sanción de los ilícitos económicos no debe entenderse como una renuncia estatal al ejercicio de funciones propias sino, al contrario, como un mecanismo por el cual el Estado se vale de las empresas para lograr una intervención mucho más eficiente (Montiel 2017, 29). Por otro lado, tampoco resulta vano recordar que una regla elemental de eficiencia económica aplicada al Derecho consiste en atribuir la obligación de prevenir un daño a aquella de las partes involucradas que puede hacerlo al menor costo. Paralelamente, quien puede evitar un daño al menor costo y decide no hacerlo, debe cargar con las consecuencias legales de tal omisión.

Para ilustrar por qué resulta socialmente eficiente que la responsabilidad de disuadir cierto tipo de criminalidad económica compleja recaiga principalmente en las empresas mediante la adopción de programas de compliance, y no sobre el Estado a través de los mecanismos ordinarios del Derecho Penal, podemos recurrir a un sencillo ejemplo. Supongamos que las autoridades buscan disuadir la comisión de delitos de corrupción que generan un perjuicio anual al erario público 100000000 dólares. Para ello, existen básicamente dos opciones: a) financiar un aparato judicial destinado a investigar y juzgar la corrupción que implica un costo presupuestario anual de 70000000 dólares; o b) "tercerizar" dichas funciones en las propias empresas a un costo para ellas de 30000000 dólares más 5000000 dólares destinados al sistema administrativo encargado de aplicar multas $u$ otras sanciones a aquellas personas jurídicas que han permitido delitos por carecer de un programa adecuado de compliance.

En este ejemplo, la opción de mantener un sistema de Derecho Penal tradicional en el que la autoridad estatal es la encargada de perseguir y sancionar a los individuos que cometen delitos económicos genera un beneficio social neto de 30000000 dólares anuales (los 100000000 dólares anuales que se evitaron en corrupción, menos los 70000000 dólares que cuesta mantener en funcionamiento el sistema), mientras que el sistema basado en la responsabilidad administrativa de las personas jurídicas y la consecuente privatización de los sistemas de control mediante la adopción de programas de compliance redunda en un beneficio social neto de 65000000 dólares, lo que lo hace evidentemente más eficiente.

Suponiendo un contexto como el descripto, el ordenamiento jurídico puede promover la adopción de los programas de compliance diseñando un sistema de responsabilidad de las personas jurídicas - penal o administrativa- que establezca los incentivos adecuados para que esa opción resulte la más conveniente económicamente para las empresas. Al respecto, se ha dicho que "(...) la responsabilidad penal de las personas jurídicas puede conformarse como el sistema de cierre de los distintos modelos de autorregulación administrativa, que han aparecido además en los sectores -consumidores, protección de accionistas, medio ambiente, trabajadores, mercados financieros, blanqueo de capitales, etcétera- donde la responsabilidad colectiva tiene un mayor sentido" (Nieto Martín 2008, 14). Del mismo modo, se ha señalado que "el principal objetivo de la responsabilidad colectiva sería incitar la autorregulación dirigida a la prevención del delito en el seno del ente colectivo, ante la incapacidad de los Estados para realizar eficazmente dicha función, y efectuar una administración a largo plazo de los riesgos modernos" (Boldova Pasamar 2013, 226).

En definitiva, el modo en que la política criminal busca incentivar la adopción por parte de las empresas de mecanismos de prevención activa de los delitos cometidos en el contexto de su actividad, es el establecimiento de sistemas de responsabilidad penal de las 
personas jurídicas, en las que éstas responden por los ilícitos penales cometidos por sus directivos o dependientes, excepto que demuestren que han implementado un programa de compliance eficaz, y que ni aún mediante este obrar corporativo diligente, el delito pudo ser evitado. En este orden de ideas, el compliance y la responsabilidad de las personas jurídicas constituyen dos aspectos complementarios de una misma estrategia político-criminal orientada a la prevención eficaz de los delitos económicos. Al respecto, se ha señalado que, en términos clásicos de criminología, el compliance supone una estrategia de prevención primaria, en tanto que la responsabilidad penal o administrativa de los entes ideales opera en la prevención secundaria (Montiel 2017, 25).

Está claro que, para que las empresas adopten sistemas de prevención y control que resulten en verdad socialmente provechosos, la legislación debe calibrar adecuadamente el contenido de las obligaciones que pone a cargo de las personas de existencia ideal y las consecuencias que acarrea su incumplimiento. Si las normas imponen a las empresas la adopción de sistemas de compliance demasiado estrictos o gravosos en relación a los riesgos que se busca prevenir o a la dimensión de su giro comercial, o resultan extremadamente restrictivas a la hora de atenuar o eximir la responsabilidad de quienes han hecho sus mejores esfuerzos para prevenir la comisión de actos ilícitos, su implementación resultará un fracaso. Ante un panorama en el que la adopción de los mecanismos internos de prevención del delito que impone la legislación sólo acarrea costos y poco o ningún beneficio potencial, las empresas simplemente optarán por omitirlos y afrontar las eventuales consecuencias, o enfocarse en otras actividades con regulaciones menos severas lo cual, como veremos, afectará la dinámica del mercado y el bienestar general. En este orden de ideas, no puedo menos que coincidir en que:

“(...) no basta con que la regulación legal recomiende, estimule e incluso disponga la conformación de un criminal compliance en la empresa, sino que deben darse, además, las condiciones para que tal conformación resulte económicamente atractiva para las empresas. Si la propia existencia o viabilidad económica de la empresa se contrapone finalmente a la lógica del cumplimiento normativo, queda claro que de nada servirá que la legislación promueva la conformación de este tipo de mecanismos empresariales. La empresa es lugar por antonomasia donde se realiza siempre un análisis costobeneficio. El sinalagma es sencillo: si con el desarrollo del compliance program resulta menos beneficioso cometer la infracción y asumir las consecuencias, que no implementarlo, las empresas optarán por no bosquejarlo" (Arocena 2017, 136).

En definitiva, si bien es cierto que, en muchos casos, establecer un sistema legal de responsabilidad de las personas jurídicas por los delitos cometidos por sus directivos o dependientes, que tenga por objeto incentivar la implementación de programas de compliance, puede ser un método eficaz para minimizar el costo social de la criminalidad corporativa, no por ello debe caerse en el error de suponer que esa sea una afirmación universalmente válida. Una legislación inteligente, que busque efectivamente disminuir el daño social del delito y promover mayores niveles de bienestar general, debería ponderar al menos dos aspectos centrales al momento de determinar si resulta conveniente promover la adopción de programas de compliance (y delinear sus características y alcance, llegado el caso), mantenerse en un sistema de responsabilidad penal estrictamente individual o, directamente, desincriminar ciertas conductas: (i) el tipo de empresas a las que se dirige la regulación, atendiendo a su tamaño, estructura organizativa, actividades que desarrolla, etcétera; y (ii) el tipo de actividad a la que se apunta, evaluando las características del respectivo mercado, la clase y alcance de los riesgos que se busca disuadir y la relevancia que tiene para el nivel de actividad económica general entre otras cuestiones.

Sobre estos aspectos, y sin perjuicio de aquello en lo que ahondaré más adelante, corresponde señalar que existe cierta tendencia a diseñar los sistemas de responsabilidad de las personas jurídicas atendiendo a la problemática que presentan las grandes empresas con estructuras organizativas altamente complejas, sin tener en cuenta la situación muy distinta que ofrecen las pequeñas y medianas empresas con organigramas mucho más simples y acotados. Tal podría ser el caso, por ejemplo, del Código Penal español o de la ley argentina 27.401 .

En estos casos, que son en rigor, los que pueblan mayoritariamente los escritorios judiciales, al menos en Latinoamérica, no se verificaría el supuesto de que la investigación estatal del delito es sumamente compleja y costosa, sino que, por el contrario, ésta puede ser concluida exitosamente en forma rápida si media una actuación diligente de fiscales y jueces. Asimismo, para este tipo de empresas la implementación de sistemas de vigilancia y control interno puede representar una pesada carga administrativa y económica, que afectaría negativamente la viabilidad económica de su actividad. A todo esto, cabría agregar que el potencial daño causado por ilícitos cometidos con la intervención de pequeñas y medianas empresas sería, en virtud de su menor dimensión económica, también significativamente más bajo que el ocasionado por organizaciones de mayor tamaño. 
Volviendo a nuestro esquemático ejemplo de párrafos anteriores, podríamos ilustrar la situación suponiendo que, en estos casos, el costo del sistema penal "tradicional" es de 30 000000 dólares, el daño causado por los hipotéticos delitos de 50.000 .000 dólares, y el costo de los programas de compliance para las empresas, más el sistema de sanciones administrativas destinado a respaldarlo, de 35000000 dólares. Bajo estos presupuestos, inducir a las personas jurídicas más pequeñas a adoptar programas de control interno resultaría económicamente ineficiente y, por lo tanto, injustificado.

Por otra parte, a este panorama deberíamos agregar que, en muchos casos, el costo del programa de compliance tendría un peso relativo mucho mayor en el costo operativo total de una pequeña empresa que en el de una gran corporación multinacional, lo que impondría a la primera una desventaja competitiva que constituiría una verdadera barrera de ingreso a ciertos mercados, con el consecuente perjuicio para la competencia en general y la concentración de la actividad en unos pocos grandes jugadores.

Como se ve, el diseño de las normas que se adopten para disuadir los distintos delitos vinculados a la actividad empresarial, y los criterios que se desarrollen para su efectiva aplicación, tienen consecuencias económicas que es necesario ponderar en cada caso concreto. La adopción irreflexiva de ciertos modelos legislativos, por presunta imposición de compromisos internacionales o mera moda doctrinaria, puede acarrear efectos contraproducentes que es menester evitar. Seguidamente, ahondaremos un poco más en ciertas herramientas conceptuales que pueden resultar útiles en el análisis de estas cuestiones.

\section{Efectos de los programas de compliance sobre la actividad de la empresa}

Hemos visto hasta aquí algunas de las razones por las cuales establecer sistemas de responsabilidad penal o administrativa de las personas jurídicas que induzcan a éstas a adoptar programas de compliance puede ser, en determinadas circunstancias, un medio idóneo para mejorar la eficiencia del sistema penal. En este punto, quisiera detenerme a reflexionar brevemente respecto del modo en que este tipo de herramientas normativas afectan el funcionamiento de la empresa y la actuación de ésta en el mercado.

En primer lugar, debemos considerar que las organizaciones moldean, o al menos influyen palpablemente, las decisiones de los individuos que actúan en ellas, lo que puede propiciar o desalentar la comisión de delitos. Lejos estoy de caer en los desvaríos funcionalistas que ven en las empresas entes con capacidad de organizarse a sí mismos y utilizar a los individuos como un medio para la consecución de fines que son ajenos a su voluntad, o de una mirada anticapitalista que supone que la actividad empresarial conforma "(...) un ambiente criminógeno propicio para la gestación, aprendizaje y reproducción de actividades ilícitas" (Raza Castañeda, 2016). Sin embargo, las normas explícitas e implícitas que rigen a las organizaciones, e incluso los valores que informan su funcionamiento, condicionan el accionar de los individuos que las integran, al alterar sus estimaciones personales de costo-beneficio, lo que a su vez influye en las decisiones de los demás miembros de la empresa. De hecho, esta capacidad de las normas internas de la empresa para constreñir el accionar de sus directivos y dependientes es lo que fundamenta la adopción de los programas de compliance y justifica la imposición de sanciones a la persona jurídica por los delitos cometidos por individuos que ponen de manifiesto su insuficiencia como mecanismo disuasivo, ya sea por su diseño deficiente o su implementación defectuosa.

Siguiendo esta línea de ideas, Aguilera Gordillo señala que es la escuela del Nuevo Institucionalismo la que explica la interacción entre individuos e instituciones, cómo las personas que componen una organización crean reglas de juego que influyen sobre ellos mismos y sobre otros actores y, en definitiva, el impacto que esto tiene en el diseño de políticas vinculadas a la criminalidad económica:

"Este presupuesto, explicaría con solvencia en el ámbito jurídico-penal, la implementación de la responsabilidad de la persona jurídica en un modelo donde sólo el individuo tiene capacidad para realizar la conducta delictiva (en un sistema de corte vicarial, en definitiva), pero donde existen constricciones, influencias y regulaciones internas que influyen cuando éste es miembro de una organización. Y ello, vendría a fundamentar la propia existencia de los compliance programs: la conducta penalmente relevante es la que deviene de la decisión de la persona física, pero en la medida en que ésta siempre toma en consideración el contexto social, es decir, la persona jurídica en la que se inserta, atribuir a ésta consecuencias negativas derivadas de su forma de proceder condicionará su propia toma de decisiones (delictivas). Al mismo tiempo, al suponer constricciones a las que se someten las decisiones individuales, los compliances o modelos de organización y gestión resultan absolutamente necesarios para limitar o encauzar la capacidad de decisión del sujeto individual haciéndole 
desistir del comportamiento delictivo y fomentar conductas de cumplimiento normativo" (Aguilera Gordillo 2018, 227-228).

Para ilustrar esta retroalimentación entre las reglas institucionales y las decisiones de los individuos, podemos recurrir a un ejemplo. Imaginemos una empresa farmaceútica que estatuye un importante premio por productividad para sus vendedores, y al mismo tiempo carece de cualquier tipo de controles y sanciones para el comportamiento antiético de su personal. En este contexto, un vendedor comienza a ofrecer pequeños sobornos (inferiores al monto del premio por productividad, obviamente) a los responsables de compras de clínicas y hospitales, incrementando las ventas. Al percatarse de que este vendedor recibe el premio por productividad y no es sancionado por las autoridades de la empresa por su comportamiento ílícito, el resto de los vendedores se ve incentivado a imitar esa estrategia, e incluso ir cada vez un poco más lejos. No sería de extrañar que, al poco tiempo, conductas como el soborno, el engaño respecto de las propiedades de los productos ofrecidos e incluso su adulteración, se tornen generalizadas.

Existe evidencia empírica que, en este sentido, sugiere que las conductas ilícitas en el ámbito de las empresas se incrementan siguiendo un efecto de "pendiente resbalosa", en el que las infracciones menores no sancionadas de algunos empleados conducen a que ellos mismos y los demás empleados vayan incurriendo en actos crecientemente más graves, incluso delictivos. De ello se sigue que resulta conveniente que las organizaciones sancionen consistentemente incluso las conductas antiéticas menores, lo que promueve un ambiente de apego a ley que desalienta efectivamente la comisión de delitos por parte de sus miembros (Welsh, Ordóñez, Snyder \& Christian 2014, 12).

Vemos entonces con claridad de qué modo las reglas establecidas por una empresa en relación a su personal y directivos, sumadas a la falta de controles respecto de conductas antiéticas o directamente ilícitas, pueden generar incentivos para la comisión de delitos y, por ende, justificar la imposición de sanciones a la persona jurídica en virtud de su organización defectuosa. El propósito de estas sanciones, como se ha señalado anteriormente, no es otro que inducir a un cambio de las reglas explícitas e implícitas que rigen el funcionamiento interno de la empresa, como medio, a su vez, de prevenir la comisión de ilícitos. En este orden de ideas se ha señalado que:

"(...) el compliance y los programas de cumplimiento normativo constituyen mecanismos orientados a instrumentalizar una cultura corporativa en el que el cumplimiento de la ley constituya un valor que se impregna en los diversos componentes de la estructura empresarial. El efecto preventivo del compliance se puede reconocer a partir de los hallazgos de la criminología que permite advertir cómo es que la cultura empresarial impacta en las personas naturales que interactúan dentro de la estructura empresarial" (Reyna Alfaro 2015,475$)$.
Desde este punto de vista, si la legislación introduce incentivos para que las empresas implementen sistemas internos de control y prevención de ilícitos, ello podría cambiar a su vez los incentivos de los individuos que actúan en la organización e inducirlos a perseguir sus propios fines por vías lícitas. Retomando el ejemplo de la empresa farmacéutica, si el premio por productividad es acompañado por un programa de compliance que establezca fuertes sanciones para los comportamientos antiéticos, genere canales de denuncia anónimos para que el propio personal de la empresa y sus clientes informen actos ilícitos, promueva investigaciones internas frente a esas denuncias, sancione una política que defina claramente las situaciones de conflicto de intereses, etc., es probable que los vendedores concentren sus energías en tratar de ser más persuasivos con sus clientes en lugar de intentar sobornarlos.

El peligro aquí consiste en que, por imponer estándares demasiado estrictos para los sistemas de compliance, la legislación termine desincentivando cierto tipo de actividades no sólo lícitas, sino incluso deseables en el seno de las empresas. De este modo, reglas demasiado rígidas en aspectos tales como conflictos de intereses, evaluación de nuevos socios de negocios o responsabilidad por productos riesgosos, podrían determinar a los miembros de la organización a adoptar una postura excesivamente conservadora, refractaria a los cambios y a la innovación, que terminaría repercutiendo negativamente en la productividad y rentabilidad de la firma. Al respecto, coincido en que "es necesario no caer en las denominadas trampas disuasorias. Se trata de evitar sanciones o penas tan gravosas para las empresas que esa desproporción se relacione con un riesgo que coarte injustificadamente la cultura del emprendimiento, la investigación o el fomento de creación de nuevas empresas" (Aguilera Gordillo 2018, 214).

Del mismo modo, se debe procurar evitar que sanciones demasiado gravosas -ya sea por su monto, o por resultar demasiado restrictiva la admisión de circunstancias atenuantes o eximentes de responsabilidad- o la obligación legal de establecer un programa de compliance excesivamente complejo y minucioso, y por ende costoso de implementar, terminen disuadiendo a las empresas de continuar con 
sus actividades, o las lleven a concentrarse en otros mercados. Debemos tener en cuenta, en este sentido, que bajo un sistema que no admita la defensa basada en haber establecido un programa de prevención razonablemente eficaz, la única vía que les quedaría a las empresas para evitar sanciones por los delitos cometidos por sus miembros consistiría en reducir el nivel de las actividades potencialmente riesgosas o abandonarlas definitivamente (Posner 2007, 290).

En este sentido, resulta necesario insistir en que, para que el sistema resulte eficiente, las sanciones deben resultar proporcionadas con el daño que procuran evitar. Por su parte, resulta a priori inconveniente establecer pautas demasiado rígidas a las que deban acogerse los programas de compliance, sin tener en cuenta las características particulares de cada empresa. Por el contrario, la legislación debería limitarse a definir ciertas pautas generales, dejando librado a cada empresa adoptar los mecanismos que mejor se adapten a su actividad y riesgos particulares, las características de su organización o sus posibilidades económicas, en la medida en que pueda determinarse su real efectividad.

Por último, y a los efectos de no imponer a las empresas costos desproporcionados que desalienten innecesariamente su actividad con el consecuente perjuicio para la economía en su conjunto, la efectividad de los programas de compliance debería evaluarse atendiendo a las particularidades de cada organización, y teniendo en cuenta los riesgos que efectivamente se busca neutralizar. De este modo, no pueden aplicarse idénticos estándares al evaluar el compromiso con el cumplimiento normativo de una gran empresa multinacional con un organigrama altamente complejo, intrincados flujos financieros y gran disponibilidad de recursos, que el de una pequeña firma familiar con escaso giro comercial y decisiones concentradas en unas pocas personas. Va de suyo que, en este último caso, exigir cuestiones tales como la designación de un oficial de cumplimiento con autonomía del directorio, la implementación de un canal de denuncias anónimas o exhaustivas normas de conocimiento de socios comerciales, resultaría a la vez ruinoso para la empresa e innecesario para la prevención del tipo de delitos en que se puede ver involucrada.

\section{Efectos sobre la competencia}

En el apartado anterior vimos cómo la adopción de un programa de compliance puede incidir hacia el interior de la empresa, en aspectos tales como el tipo de decisiones que adoptará su dirección o el nivel de sus actividades, dependiendo de qué tan rigurosas sean las obligaciones que se derivan del programa y el costo que implique su adopción.

Ahora bien, si la adopción -ya sea voluntaria o por imposición legal- de un programa de compliance con determinadas características influye en las decisiones de cada empresa en relación a su actividad, de ello se sigue lógicamente que la agregación de estas decisiones empresariales individuales terminará surtiendo efectos en la dinámica y configuración de los distintos mercados en que ellas actúan. Sin llegar a la exageración de suponer que el tipo de programa de compliance que adopten las empresas, su costo en relación a las ganancias esperadas y las consecuencias legales de su falta de adopción son absolutamente determinantes en la configuración de un mercado, ciertamente podemos afirmar que los mencionados son factores que, en mayor o menor medida, pueden influir en el tipo, cantidad y comportamiento de los actores que compiten en determinado sector de la economía. Así, las normas sobre responsabilidad de las personas jurídicas y compliance pueden convertirse en ocasiones en obstáculos para la competencia, favoreciendo la concentración de los mercados, o constituir un desincentivo para la realización de ciertas actividades, contribuyendo a la disminución de los niveles de producción. Estos aspectos deberían ser, como otros ya revisados, debidamente ponderados a la hora de legislar sobre los programas de integridad y sus consecuencias legales.

Para analizar estas cuestiones, podemos plantear un esquema de distintos escenarios, a partir del cual hipotetizar sobre los efectos que tendría en un determinado mercado la exigencia legal de adoptar un programa de compliance por parte de las empresas que actúan en él. En segundo lugar, vamos a suponer que la normativa puede establecer criterios muy estrictos para aceptar la atenuación o eximición de responsabilidad a las personas jurídicas que han establecido mecanismos internos de prevención y control de los riesgos penales, o bien puede adoptar criterios más flexibles, que permitan escapar de las sanciones con mayor facilidad. En tercer lugar, habrá que tener en cuenta si los programas de compliance resultan o no costosos en relación a los beneficios que espera obtener la empresa de la actividad, aclarando que ese mayor o menor costo puede derivarse de la naturaleza propia de los riesgos que se busca prevenir o de las exigencias impuestas por el sistema legal. Finalmente, será menester ponderar si, en la actividad que se analice, el riesgo de que los individuos vinculados a la empresa se vean involucrados en ilícitos penales es alto o bajo.

Por otra parte, y en relación a las empresas que actúan en el mercado, podemos suponer 
que existen empresas de "alta reputación", que tienen por política cumplir rigurosamente sus obligaciones legales (por ejemplo, por exigencias de sus casas matrices en el extranjero), y empresas de "baja reputación", que no tienen mayor interés en apegarse estrictamente a la normativa vigente, y exhiben tendencia a tomar atajos legales o asumir mayores riesgos.

Todo ello nos da como resultado el siguiente esquema, en el que podemos identificar ocho escenarios distintos, que seguidamente analizaremos:

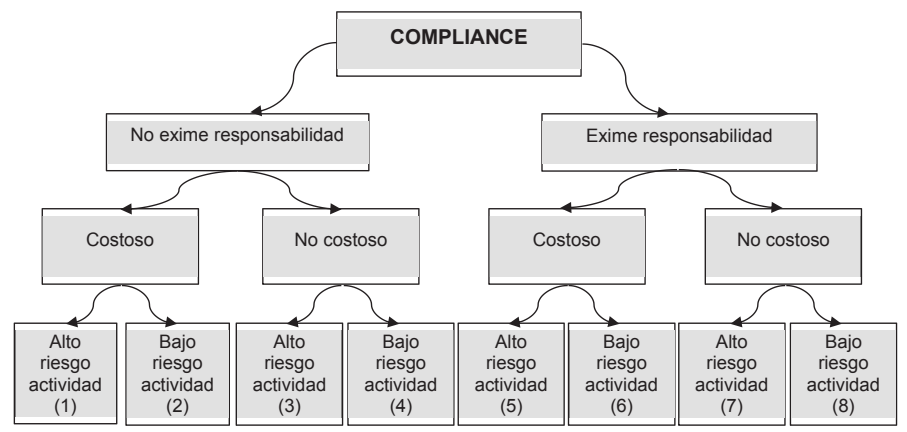

En el escenario identificado como (1), el programa de compliance no exime de responsabilidad a las empresas, adoptarlo es costoso en relación a las ganancias esperadas, y el riesgo de incurrir en delitos vinculados a la actividad es alto. Claramente no existen incentivos para que las empresas adopten programas de integridad eficaces, por lo que cabe suponer que las empresas de alta reputación se mantendrían al margen de la actividad. La cantidad de actores en este mercado tendería a ser reducida -dado que pocos estarían dispuestos a asumir los riesgos de sanciones-, y consistente básicamente en empresas poco comprometidas con el cumplimiento de la normativa vigente, aspectos que llevarían a la reducción del nivel de actividad en el sector y la potenciación del riesgo de conductas ilícitas.

La situación descrita en el párrafo precedente es similar en el escenario (2), aunque con la diferencia de que, en virtud del menor riesgo de la actividad, sería esperable que participe una mayor cantidad de competidores. Sin embargo, toda vez que la competencia está básicamente circunscripta a empresas sin un interés real en la prevención de los riesgos penales -dado que sigue sin haber incentivos para la adopción de programas de compliance realmente eficaces-, es esperable que los niveles de riesgo tengan una tendencia a la suba.

En el escenario (3) aparecen ciertos incentivos para que empresas de alta reputación adopten mecanismos de prevención de riesgo toda vez que, si bien estos no son tenidos en cuenta como factor de atenuación o exclusión de sanciones, al ser relativamente baratos de implementar, tendría sentido su incorporación en la medida en que conduzcan a una efectiva reducción del riesgo. En este caso, el mercado, si bien acotado en la cantidad de competidores por su alto riesgo, mostraría una competencia entre empresas de baja y alta reputación, teniendo estas últimas cierta ventaja competitiva en la medida que el costo del programa de compliance sumado al costo esperado de sanciones derivadas de hechos no evitables, resulte inferior al costo esperado de las sanciones por aquellas empresas que no adoptan ningún tipo de prevención eficaz. La preponderancia de las empresas de alta reputación, podría conducir a una reducción de los niveles de riesgo.

Al contrario del escenario anterior, en el que planteamos como (4), si bien están dadas las condiciones para que exista una mayor cantidad de competidores -en función del bajo nivel de riesgo de sanciones-, las empresas de baja reputación, al ahorrarse el costo de implementar un programa de compliance sin que ello incremente significativamente el costo esperado por sanciones, podrían tener una ventaja competitiva sobre los competidores de mayor reputación. De darse este caso, el riesgo de que se cometan delitos en este mercado podría tender a aumentar en el largo plazo, por la falta de adopción de medidas adecuadas de prevención.

Ingresando en los supuestos en que la legislación acepta con relativa facilidad la eximición o atenuación de la responsabilidad de aquellas personas jurídicas que hubieran adoptado programas de integridad eficaces, en el escenario (5) es esperable un nivel relativamente bajo de actividad y un mercado acotado a pocas empresas: firmas grandes de alta reputación que pueden afrontar el costo del programa de compliance, y firmas grandes de baja reputación que pueden previsionar el costo de eventuales sanciones. Siempre y cuando las sanciones sean suficientemente altas como para que su costo esperado sea superior al de la adopción de un programa de compliance, las empresas de alta reputación tendrían una ventaja competitiva sobre las de baja reputación, en cuyo caso podrían ir disminuyendo los niveles de riesgo de la actividad.

En el escenario identificado como (6) podrían darse las condiciones para una mayor competencia y un mayor nivel de actividad que en el escenario (5), dado que, en función del bajo riesgo, podrían ingresar empresas de baja reputación de menor tamaño, que no se verían excluidas por el alto costo esperado de sanciones. Las ventajas competitivas de las empresas de mayor reputación tenderían a diluirse, excepto que las sanciones a aquellas empresas que no adopten programas de 
integridad se eleven a niveles lo suficientemente altos como para compensar la baja posibilidad de que sean aplicadas, lo que a su vez reduciría los incentivos para que ingresen competidores más pequeños.

El escenario en que existen mayores incentivos para la adopción de programas de compliance que realmente apunten a la disminución de los riesgos penales es el (7). Aquí no hay prácticamente posibilidad de obtener ventajas ahorrando el costo del programa, dado que este es bajo y en todo caso resultaría inferior al riesgo potencial de recibir una sanción, que es alto. Incluso las empresas que no tuvieran un interés genuino en la prevención de riesgos, tendrían un incentivo económico para adoptar un programa de prevención eficaz, salvo que el monto de las eventuales sanciones fuera demasiado bajo, compensando de ese modo su alto riesgo. En cuanto a la competencia, la exigencia del compliance no debería desalentar el ingreso de competidores al mercado ni determinar una reducción del nivel general de actividad.

Por último, en el escenario (8) no habría motivos para suponer algún tipo de afectación de la competencia ni del nivel de actividad, pero el bajo riesgo de sanciones penales podría llevar a las empresas de baja reputación a no adoptar los programas de compliance, lo que les daría una pequeña ventaja comparativa sobre aquellos que si lo hacen. Este desincentivo a la incorporación de los sistemas de prevención y gestión del riesgo podría eventualmente compensarse aumentando el monto de las sanciones, para de ese modo incrementar el costo esperado de las empresas de baja reputación. De lo contrario, podría generarse una situación propicia al aumento paulatino de los niveles de riesgo de la actividad.

Como se ve, las exigencias que el sistema legal imponga a las empresas a la hora de adoptar un programa de integridad, así como las consecuencias que establezca en materia de graduación de sanciones frente a su adopción, pueden tener influencia en los niveles de actividad y en la dinámica del mercado. Aun cuando esa influencia no sea determinante, debe ser sin embargo tenida en cuenta por el legislador a la hora de establecer las reglas de juego para cada mercado, atendiendo a sus características y a los intereses públicos involucrados en su regulación.

En este sentido, es importante pensar cada caso particular para evitar caer en normativas estandarizadas que traten a todas las situaciones por igual, con el consecuente riesgo de generar efectos socialmente contraproducentes. Al respecto, si bien nadie dudaría que, en general, lo conveniente es promover siempre mayores niveles de actividad y de competencia, podrían existir casos en los que la única forma de prevenir riesgos de daños potencialmente irreversibles sea reducir tanto uno como otro. Por ejemplo, en actividades como la minería, la generación de energía nuclear o la explotación petrolera, en que es muy grande la posibilidad de que se produzcan daños al medioambiente devastadores -que penalmente podrían constituir delitos culposos-, quizás no sería inconveniente imponer reglas muy estrictas en materia de compliance y responsabilidad de las personas jurídicas, que reduzcan el nivel de actividad hasta niveles socialmente compatibles con su alto riesgo. De modo inverso, si bien nadie dudaría que en el ámbito de las contrataciones públicas es conveniente alcanzar los máximos niveles de exigencia en materia de transparencia, reglas demasiado estrictas podrían conducir a la concentración del mercado, dificultando la competencia y por ello, paradójicamente, incrementando el riesgo de hechos ilícitos ante la falta de control cruzado entre los propios competidores.

\section{Conclusiones}

La irrupción de los sistemas de compliance como herramienta de prevención de los delitos corporativos ofrece al Derecho Penal una opción innegablemente atractiva: reducir los costos de disuasión delegando en las propias empresas las funciones de investigación y sanción de los ilícitos vinculados a su actividad. Siguiendo la lógica del análisis económico, pareciéramos encontrarnos ante una oferta difícil de rechazar, que podría contribuir a disminuir el costo social del delito en un ámbito en el que el Derecho Penal, con sus principios y garantías tradicionales, naufraga al no poder resolver el problema de enfrentarse a hechos presuntamente difíciles de investigar, potencialmente muy dañosos, pero que al mismo tiempo la población no suele percibir como peligrosos. No extraña entonces, ante este panorama, el entusiasmo con el que la legislación y la academia están acogiendo esta nueva disciplina, aun cuando algunos de sus aspectos sean difíciles de compatibilizar con las categorías de nuestra dogmática penal.

Sin embargo, el reluciente atractivo del compliance y la responsabilidad de las personas jurídicas no deberían hacernos perder de vista que se trata de herramientas potencialmente útiles, pero que lejos están de ser infalibles e incluso verdaderamente superadoras de aquellas que nos ha brindado hasta hoy el Derecho Penal en muchos casos. El Análisis Económico del Derecho, en este sentido, puede ayudarnos a identificar los efectos que la adopción de distintas reglas de compliance puede acarrear en diversos escenarios concretos, permitiendo identificar sus potenciales consecuencias en la actividad de las empresas y en la dinámica de los mercados. 
Se trata, en definitiva, de procurar que los operadores jurídicos posean los elementos de juicio suficientes para adoptar sus decisiones siendo conscientes de los efectos que estas acarrean, en lugar de guiarse exclusivamente por la influencia de sistemas jurídicos supuestamente más desarrollados, o por liso y llano snobismo intelectual. El propósito de este trabajo -que espero el lector considere cumplido a esta altura- no ha sido más que proponer humildemente algunas pautas y criterios que contribuyan a sentar las bases para un análisis más exhaustivo, mesurado y consecuente de las distintas opciones que, en el estado actual del pensamiento jurídico-penal, se ofrecen para intentar conjurar las amenazas derivadas de la denominada criminalidad económica, de modo tal que las decisiones que se adopten al respecto contribuyan efectivamente a un mayor bienestar social y no meramente a la reproducción irreflexiva de discursos importados de otras tradiciones o a la cristalización del ideario dominante de la época.

\section{Referencias bibliográficas}

Aguilera Gordillo, Rafael. 2018. Compliance penal. Régimen jurídico y fundamentación analítica de la responsabilidad penal de la persona jurídica y el compliance program. Tesis de doctorado. Universidad de Córdoba.

Arocena, Gustavo. 2017. Acerca del denominado "criminal compliance". Revista Crítica Penal y Poder, número 13, 128-145. Barcelona: Universidad de Barcelona.

Becker, Gary. 1968. Crime and punishment: an economic approach. Journal of Political Economy, Vol. 76, $\mathrm{N}^{\circ}$ 2, 169-217. Chicago: University of Chicago Press.

Boldova Pasamar, Miguel Ángel. 2013. "La introducción de la responsabilidad penal de las personas jurídicas en la legislación española". Estudios Penales y Criminológicos, volumen. XXXIII, 219-263. Santiago de Compostela: Universidad de Santiago de Compostela.

Cooter, Robert y Ulen, Thomas. 1998 (1988). Derecho y economía. Traducción de Eduardo Suárez. México DF: Fondo de Cultura Económica.
Goldman, Diego Hernán. 2017. "Análisis económico del Derecho Penal y Derecho Penal liberal: confluencias y bifurcaciones". Revista Derecho Penal y Criminología, Vol. 38, No 104, 13-74. Bogotá: Universidad Externado de Colombia.

Montiel, Juan Pablo. 2017. "Cuestiones teóricas fundamentales del criminal compliance". En Letra, Año IV, № 7, 21-47. Buenos Aires: Centro de Estudios Interdisciplinarios en Ciencias Jurídicas y Sociales.

Nieto Martín, Adán. 2008. "Responsabilidad social, gobierno corporativo y autorregulación: sus influencias en el derecho penal de la empresa". Revista Electrónica Semestral de Políticas Públicas en Materias Penales. Talca: Universidad de Talca.

Nozick, Robert. 1988 (1974). Anarquía, Estado y utopía. Traducción de Rolando Tamayo. México DF: Fondo de Cultura Económica.

Palma Herrera, José Manuel. 2017. "Presupuestos jurídicopenales de la responsabilidad penal de los entes corporativos y del sistema de 'compliance'”. En José Manuel Palma Herrera y Rafael Aguilera Gordillo, Compliances y responsabilidad penal corporativa, 15-73. Pamplona: Aranzadi.

Pérez González, Sergio. 2015. "La función de los compliance programs en la responsabilidad penal-económica de la empresa". Revista Electrónica del Departamento de Derecho de la Universidad de la Rioja, No 13, 129-142. Logroño: Universidad de La Rioja.

Posner, Richard. 2007 (2002). El análisis económico del Derecho. Traducción de Eduardo Suárez. México DF: Fondo de Cultura Económica.

Raza Castañeda, Stalin. 2016. "Funciones y problemas del compliance en la teoría de la imputación penal de las personas jurídicas". Revista de Derecho Penal y Criminología, 2016 (febrero), 209. Buenos Aires: La Ley.

Reyna Alfaro, Miguel Angel. 2015. Implementación de los compliance programs y sus efectos de exclusión o atenuación de responsabilidad penal de los sujetos obligados. En Kai Ambos, Dino Caro Coria y Ezequiel Malarino (coordinadores), Lavado de activos y compliance. Perspectiva internacional y derecho comparado, 453-485. Lima: Jurista Editores.

Rojas, Ricardo Manuel. 2000. Las contradicciones del Derecho Penal. Buenos Aires: Ad-Hoc.

Welsh, David; Ordóñez, Lisa; Snyder, Deirdre \& Christian, Michael. 2014. The slippery slope: how small ethical transgressions pave the way for larger future transgressions. Journal of Applied Psychology (26 de mayo). Washington D.C.: American Psychological Association. http://dx.doi.org/10.1037/a0036950. Fecha de consulta: 4 de noviembre de 2018. 